\title{
Extracellular Matrix in Development: Insights from Mechanisms Conserved between Invertebrates and Vertebrates
}

\author{
Nicholas H. Brown \\ The Gurdon Institute and Department of Physiology, Development, and Neuroscience, \\ University of Cambridge, Cambridge CB2 1QN, United Kingdom \\ Correspondence: n.brown@gurdon.cam.ac.uk
}

\begin{abstract}
The extracellular matrix (ECM) and its receptors make diverse contributions to development. The ECM comes in a variety of forms, including the more "standard" ECM that is internal to the animal and on the basal side of epithelial sheets, as well as the apical ECM, which is especially elaborated in the invertebrates to form the exoskeleton. ECM proteins accumulate adjacent to particular target tissues in the developing animal by a variety of mechanisms: local synthesis in the target tissue; local synthesis by migrating cells; and secretion from a distant source and capture by the target tissue. The diverse developmental functions of the ECM are discussed, including the generation of a road for cell migration, creation of morphogenetic checkpoints for differentiation, modulation of morphogen gradients, insulation of organs, gluing together cell layers, and providing structure for the organism.
\end{abstract}

$\mathrm{T}_{\mathrm{t}}^{\mathrm{h}}$ his article will discuss the many functions of the ECM that are important in animal development. First, I will discuss the production of ECM in the developing animal (see Adams and Lawler 2011, Barros et al. 2011; ChiquetEhrismann and Tucker 2011; Schwarzbauer and DeSimone 2011; Watt and Fujiwara 2011; Wickstrom et al. 2011; Yurchenco 2011), and then describe briefly the range of ways that the ECM contributes to development. Given the space constraints of this article, I will not attempt to be exhaustive in my coverage, but instead will seek to identify examples that show the different kinds of ECM function that have been revealed from studies of development. My examples will be focused on developmental processes shared between invertebrates and vertebrates, as many vertebrate-specific roles of the ECM are covered in other references that are part of this subject collection. The somewhat different compositions, arrangements, and developmental changes in invertebrate ECMs provide an illuminating perspective from which to consider ECM function more generally.

\section{PRODUCTION AND MODULATION OF THE ECM DURING DEVELOPMENT}

\section{How Do We Define the ECM?}

Any protein within the extracellular environment has the potential to be part of the ECM. Most ECM components are large secreted glycoproteins, but some are initially membrane

Editors: Richard O. Hynes and Kenneth M. Yamada

Additional Perspectives on Extracellular Matrix Biology available at www.cshperspectives.org

Copyright (C) 2011 Cold Spring Harbor Laboratory Press; all rights reserved; doi: 10.1101/cshperspect.a005082

Cite this article as Cold Spring Harb Perspect Biol 2011;3:a005082 
N.H. Brown

linked and then cleaved to release an extracellular domain. Many ECM components are large glycoproteins, however not all, and furthermore, small soluble secreted signaling molecules do become associated with the ECM, and whether that makes them an ECM component or simply regulated by their association with the ECM is a matter for debate (see Hynes and Naba 2011). From a practical point of view, we expect most components of the ECM to form discrete matrices where the components have low solubility or have become insoluble by crosslinking between components. This is revealed by clear concentration of ECM components at discrete sites in the developing animal, rather than being diffusely distributed within the extracellular fluid.

For those working with invertebrates, we have come to appreciate that epithelial cells are associated with two ECMs: one on the basal surface and another on the apical surface, which forms the exoskeleton. Electron microscopy shows that invertebrate epithelial cells contain hemiadherens-like or hemidesome-like structures not only at the basal surface, but also at the apical surface (Mogensen and Tucker 1987; Francis and Waterston 1991; Tepass and Hartenstein 1994). In insects, the basal junctions contain integrins, but the components of the apical junctions have yet to be discovered. In Caenorhabditis elegans, the basal junctions contain myotactin (and not integrins), whereas two proteins distantly related to matrilins are transmembrane components of apical adhesions (for references see Zhang and Labouesse 2010) The basal ECM of invertebrates shares many components with vertebrate ECMs (see Hynes and Naba 2011; Yurchenco 2011), but also contains novel proteins, e.g., tiggrin in Drosophila (Fogerty et al. 1994). The apical ECM (aECM) contains a mixture of components that are unique to invertebrates and those that are conserved with vertebrates (Page and Johnstone 2007; Moussian 2010). Unique components include cuticlins and chitin-binding proteins, and conserved components include collagens in $C$. elegans and proteins that contain a zona pellucida (ZP) domain. ZP domain proteins are generally transmembrane proteins that are cleaved by furins to release a portion of the extracellular domain, which then assembles into an extracellular network (see Plaza et al. 2010). Examples of these matrices in vertebrates include the zona pellucida surrounding the egg and the tectorial membrane of the inner ear. Importantly, ZP proteins are not only required for the association of the aECM with the apical surface, but also play a role in specifying cell and tissue morphology. These findings have led to the realization that the exoskeleton is not simply a protective covering, but also contributes to morphogenesis.

Although these apical and basal ECMs are normally kept distinct, two proteins have recently been discovered in Drosophila that are essential to prevent basement membrane proteins accumulating on the apical surface of epithelia (Denef et al. 2008; Sorrosal et al. 2010). The polarized distribution of transmembrane proteins, such as integrins, is not disturbed, indicating a specific mechanism to target ECM proteins to the basal surface.

\section{Synthesis Locally or at a Distance: Role of Diffusion in ECM Formation}

Diverse mechanisms underlie the assembly of ECMs at discrete sites in the developing animal (see Fig. 1). Two opposing strategies can be envisioned, and there is evidence that both occur. In the first, the ECM component is made locally by the cells at the site of its assembly, and it rapidly becomes insoluble. The cells that make the ECM could be part of a multicellular tissue, or they could be individual cells that migrate to specific sites to secrete a matrix at that site. In the second strategy, the ECM protein is secreted into the extracellular fluid, where it diffuses freely, and becomes assembled into matrices at specific sites by the restricted expression of a receptor or a locally synthesized nondiffusible ECM component.

A number of experiments have shown that ECM proteins can diffuse extensively before forming extracellular matrices (Bunch et al. 1998; Huang et al. 2003; Medioni and Noselli 2005). There are also good examples of local ECM synthesis (Martin et al. 1999; Chanana 


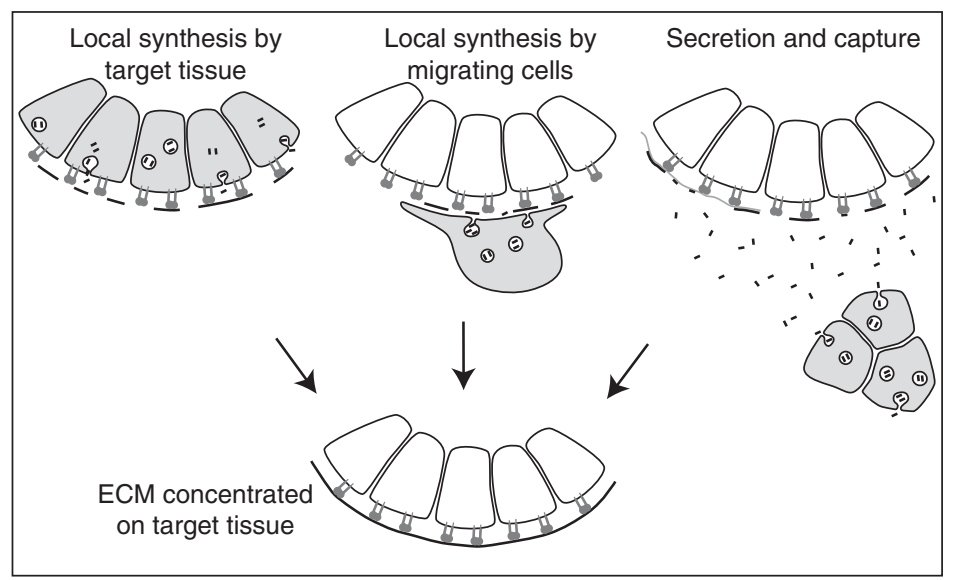

Figure 1. Different mechanisms leading to localized accumulation of ECM adjacent to a target tissue. For the two involving local synthesis, accumulation could be receptor independent (left side of each tissue) or receptor dependent (right side of each tissue). Capture requires interaction with a protein localized on the target tissue, either another ECM protein (left side of tissue) or receptor (right side).

et al. 2007; Subramanian et al. 2007) and cells that need to migrate appropriately to deposit matrix on a developing tissue (Bunt et al. 2011).

\section{Role of Receptors in Assembly}

The relationship between the localized assembly of the ECM and the concentration of ECM receptors into discrete junctions is the great "chicken and egg" problem in ECM biology. Does positioning of receptors first permit capture of ECM proteins at discrete sites, or does initial ECM localization drive the recruitment of receptors? At least in some cases the answer appears to be both, with sequential interactions between ECM and receptors (see also Geiger and Yamada 2011; Wickström et al. 2011; Yurchenco 2011). A good model for investigation of this issue is the Drosophila muscle attachment site.

At the discrete sites where muscle ends attach to each other and to the specialized epidermal cells called tendon cells, a tendon matrix is formed. Three components of this matrix have been characterized: tiggrin (Fogerty et al. 1994); one of the two laminins (wing blister laminin/ $\alpha 1,2 \beta \gamma$ ) (Martin et al. 1999); and thrombospondin (Chanana et al. 2007;
Subramanian et al. 2007). Tiggrin is synthesized by cells at a distance from the muscle attachments, the fat body and hemocytes, whereas the other two are synthesized locally by the tendon cells. The accumulation of wing blister laminin requires integrins (Devenport et al. 2007), but the other two can still accumulate at the ends of muscles in the absence of integrins (Fogerty et al. 1994; Martin-Bermudo and Brown 2000; Subramanian et al. 2007). In the muscles, the cytoplasmic domain of the integrin $\beta$ subunit is sufficient to drive localization of an unrelated transmembrane protein to muscle ends (Martin-Bermudo and Brown 1996), and the reciprocal is also true, as an integrin lacking both $\alpha$ and $\beta$ cytoplasmic tails localizes to muscle ends (MD Martin-Bermudo and $\mathrm{NH}$ Brown, unpubl.), suggesting that binding to ECM ligands helps localize integrins to muscle ends. Thus, we can envision a scenario in which the accumulation of tiggrin and thrombospondin helps to concentrate integrins, which in turn assist in the accumulation of wing blister laminin, building up and strengthening the tendon matrix. Such progressive building up of adhesive structures has also been observed in focal contact assembly in vertebrate cells (see Geiger and Yamada 2011). 
N.H. Brown

\section{Changes in ECM Composition}

An important aspect of the ECM in relation to development is how the composition of the ECM changes as development progresses, and how certain ECM components are restricted in their expression to certain developing tissues. This is especially true in vertebrates, in which the ancestral genome duplications have given four copies of each metazoan gene to use in new ways, and thus a great increase in the potential for tissue-specific regulation and diversification of function. Some well documented examples include the local synthesis of fibronectin to drive branching in the mouse salivary gland (Sakai et al. 2003), and the importance of asymmetric distribution of ECM to produce asymmetric looping of the gut in Zebrafish (Kurpios et al. 2008; Yin et al. 2010). Another good example of the importance of changes in ECM structure in development is provided in C. elegans by the need for the uterine anchor cell to push through the basement membrane to connect to the vulva (e.g., Matus et al. 2010).

\section{ECM FUNCTION DURING DEVELOPMENT}

\section{Types of ECM Function}

A priori, we can think about ECM function in two ways. The first is an active or directive way, in which it imparts specific information to the cells that come in contact with it. The second is a passive or supportive role, in which it helps maintain the structure of tissues and the organism, without directing cellular behavior. It is not always easy to distinguish these roles, and many ECM structures are likely to contribute both functions. We will explore this further by examining diverse developmental events, which provide examples of the different kinds of ECM function. Examples of the functions discussed are diagrammed in Figure 2.

One issue to consider regarding signaling by the ECM is that many assays performed in cell culture are over a short time frame, e.g., within the first hour or less after cells in suspension contact the ECM. Such an abrupt interaction of a cell with the extracellular matrix may occur within the developing embryo when migrating cells move onto a new ECM, but most cells play a role in building up the ECM with which they are in contact, and stay in close association for the entire lifetime of the cell. This is highlighted by the recent finding that interaction with the ECM is required to prolong the signaling by other pathways, causing cell differentiation (Xu et al. 2009).

\section{The ECM as a Road for Cell Migration}

The ECM is often used as a substrate for migration during development. However, it is important to point out that the ECM is not the substrate for all developmental migrations, and that cells can migrate directly over cells. Perhaps one of the best examples of this is the migration of the border follicle cells over and between the nurse cells in the Drosophila egg chamber; cadherins are required for this migration, but not integrins (Niewiadomska et al. 1999; Devenport and Brown 2004). As an aside, border cells create an unusual small cap of ECM, containing the basement membrane components laminin, perlecan, and collagenIV, that "leads" the migration at the first stages, but the function of this is unknown (Medioni and Noselli 2005). There are now two examples in which cells have been generated that completely lack integrins. In Drosophila, embryos and clones of cells have been generated that lack the only two $\beta$ integrin subunits encoded in the genome (including the removal of any maternal contribution) (Devenport and Brown 2004). In the mouse, leukocytes were generated that completely lack integrins by combining mutants in the integrin subunits $\alpha \mathrm{V}, \beta 1, \beta 2$, and $\beta 7$ (Lammermann et al. 2008). In both cases, some cell migration was still observed, so that the diverse migratory events could be divided into integrin-dependent and -independent. In leukocytes, extravasation and migration on 2D substrates required integrins, whereas migration through a $3 \mathrm{D}$ environment in the lymph node did not. This separation also fits with the function of integrins in the Drosophila embryo. The integrin-dependent migrations occur over a single highway, built by a palisade of developing visceral mesoderm 


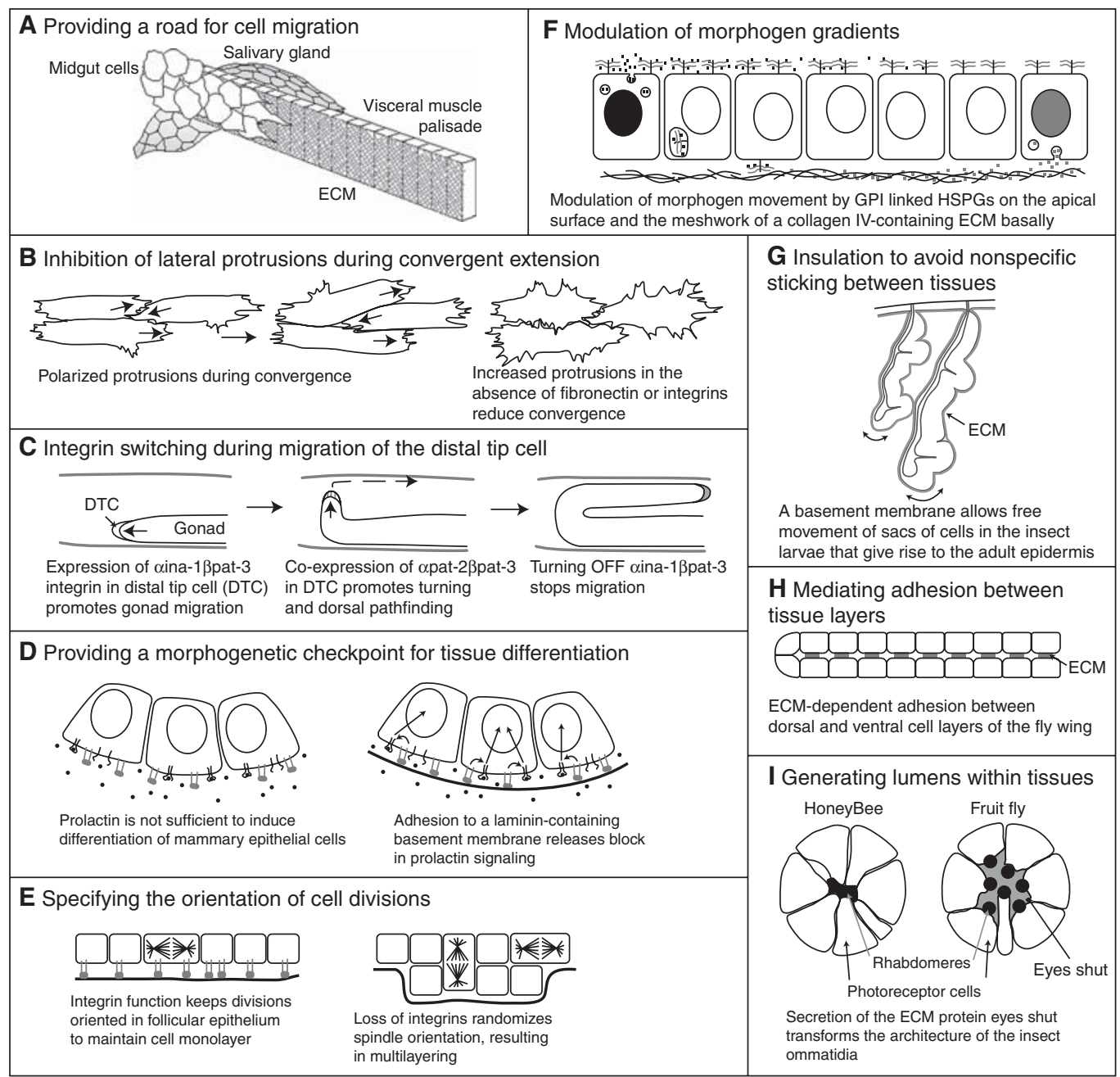

Figure 2. Examples of ECM functions in development. See text for details.

cells (Fig. 2A). The midgut forms by the migration of two pools of precursor cells toward each other on this track (Roote and Zusman 1995; Martin-Bermudo et al. 1999), the inner visceral branch of the tubular tracheal system migrates across it (Boube et al. 2001), and the salivary gland migrates caudally along it (Bradley et al. 2003). Given the diverse directions of travel along this road, it seems most likely that the direction of movement is imparted by the moving cells, and that the visceral mesoderm-associated ECM provides a passive yet essential track. This is similar to the passive role that integrins and the ECM play in vertebrate neural crest migration. Although the ECM provides a useful track for migration, it is primarily other factors that guide the direction of migration (Kuriyama and Mayor 2008). The integrin-independent migrations in Drosophila include that of primordial germ cells (Devenport and Brown 2004), and the other branches of the tracheal system (Boube et al. 2001), and although axon pathfinding is perturbed (Hoang and Chiba 1998), it is not blocked (the role of integrins in the nervous system is discussed more fully in the chapter by Barros et al. 2011). Although integrin-independent, it is possible that these may still require interaction with the ECM. 
N.H. Brown

The role of integrins in the earliest cell migration movements of gastrulation varies among species. Integrins are required for gastrulation in the deuterostome lineage, including sea urchins, Zebrafish, and amphibians, and for the latter two fibronectin has proved to be a crucial ligand for gastrulation (e.g., Marsden and Burke 1998; Latimer and Jessen 2009; Rozario et al. 2009 and references therein). The role of integrins and fibronectin in convergent extension is of particular interest, because polarized cell behavior requires integrin function, yet integrins do not impart cell polarity (Fig. 2B) (Davidson et al. 2006). Normally the cells that convergently extend in explants show a polarized morphology, with active protrusions at the front and back of the cell, oriented perpendicular to the axis of extension. Perturbation of integrins or fibronectin results in protrusive activity around the circumference of the cell, i.e., integrins suppress protrusions on the cell sides. Restoring integrin function in a random way, e.g., by substituting a short peptide encompassing the integrin binding site, restores polarized protrusions (see also article by Schwarzbauer and DeSimone 2011). Thus, integrins are required for the interpretation or execution of a polarized cell behavior, but are not instructive. We will encounter a similar scenario when we discuss integrin-dependent gene expression later. In contrast, worms and flies lack fibronectin, and do not require integrins for gastrulation (Leptin et al. 1989; Gettner et al. 1995; Devenport and Brown 2004).

A valuable example of integrin switching during migration is provided in C. elegans, during the arrangement of the elongated gonad within the body cavity by the migration of the distal tip cell (Fig. 2C) (Meighan and Schwarzbauer 2007). Migration requires $\alpha$ ina-1 $\beta$ pat-3 ( $\sim \alpha 6 \beta 1)$, but then $\alpha$ pat $-2 \beta$ pat $-3(\sim \alpha 5 \beta 1)$ is coexpressed to direct turning and dorsal pathfinding, followed by a repression of $\alpha$ ina$1 \beta$ pat-3 expression to stop migration. The switchover in integrins is regulated by a single transcription factor, vab-3/Pax6. It is not clear whether the main purpose of the switch is to change interactions with the ECM or the cytoskeleton or both; in a similar switch in Drosophila, the key differential function mapped to the extracellular domains (Delon and Brown 2009). It is not known in either case whether the ECM differs in this developmental progression, or is uniform throughout, but the fact that integrin expression needs to be regulated suggests that ligands for both integrins are available throughout. Such integrin switching may be a widespread mechanism for changing cellular responses to a static ECM (Meighan and Schwarzbauer 2008).

\section{The ECM and Cell Fate}

A key question about the ECM and its cellular receptors in relationship to development is whether they contribute to the specification of different types of cells, that is, do they control cell fate? In general, the answer is no; loss of ECM or ECM receptor function results in disorganization of tissues and impairment of their function, but all the relevant cell types are still made. This contrasts with the effects of disrupting other well-known developmental signaling pathways, such as Notch, Wnt, TGF- $\beta$, etc., in which the pattern of cell determination is altered. However, there are some exceptions to this general answer (see also Streuli 2009).

Disrupting ECM or integrin function impairs differentiation of mammalian myoblasts into muscles (Menko and Boettiger 1987) and mammary epithelial cells into milk-producing cells (Streuli et al. 1991), and differentiation of midgut cells in Drosophila (Martin-Bermudo and Brown 1999). Thus, there does seem to be integrin-dependent regulation of the cell differentiation. It seems logical that there might be a feedback control on tissue integrity before final differentiation.

Integrin regulation of genes often acts in synergy with other signals. For example, in the mammary epithelium, integrins and the milkinducing hormone prolactin act together to promote differentiation (Fig. 2D). One can imagine many scenarios for the integration of these two pathways; it turns out that integrins facilitate signaling by the prolactin pathway (e.g., Xu et al. 2009), rather than having an independent pathway that joins up with the 
prolactin pathway on target gene enhancers. In the Drosophila midgut, genes were identified whose normal pattern of expression required integrin function, including both up- and down-regulation (Martin-Bermudo and Brown 1999). Integrin function in gene regulation, but not morphogenesis of the tissue, could be restored by a chimeric receptor that dimerized the cytoplasmic domain of the $\beta$ subunit, ruling out nonspecific effects caused by loss of integrin adhesion. This "constitutively active" integrin signaling restored the normal pattern of the expression of these target genes, rather than giving ubiquitous expression or repression. This shows that it is not the pattern of integrin activation that produces the pattern of expression of these integrin target genes, and instead, ubiquitous integrin activity is coordinated with patterned signals to produce appropriate gene expression patterns.

Another way that interaction with the ECM can alter cell fate is by affecting the orientation of cell divisions (Fig. 2E). Divisions parallel to the basal surface will maintain cells in proximity with the basal ECM and possible signals that may maintain cell fate. Examples of integrins regulating spindle orientation include the mammalian epidermis (Lechler and Fuchs 2005) and the follicular epithelium surrounding the Drosophila ooctye (Fernandez-Minan et al. 2007).

In mammalian cells, interaction with the ECM is obligatory for the proliferation and survival of many cell types. Evidence for the role of cell-ECM interactions in establishing cell polarity comes from the behavior of MDCK and other cells when cultured in a 3D matrix (e.g., Yu et al. 2005). However, genetic loss of individual components of the ECM or cellular receptors within the organism does not severely disrupt polarity, in contrast to mutations in other components of the polarity machinery. Cells completely lacking integrins in Drosophila can polarize normally, although they do have trouble maintaining a polarized epithelium (Devenport and Brown 2004). Recently, it was discovered that dystroglycan and dystrophin are not required for apical-basal polarity in Drosophila either, unless the cells are starved, in which case they become essential (Mirouse et al. 2009).

Thus, the evidence to date argues that the ECM and its receptors are not controlling the early patterning events of embryogenesis, as cell polarity and establishment of initial cell fates occurs normally, at least in the simpler organisms. Thus, ECM-cell receptor interactions appear to function in a way that is distinct from signaling pathways involved in fate decisions, such as Notch and Wnt. Integrins are required for movement and differentiation of cells in the embryo, but apparently in a permissive way. This is not to downplay the importance of cellular interactions with the ECM, as they are critical to normal development, but rather to try to accurately represent their function. Thus, for migration one can view the ECM as the road and ECM-receptors as the vehicle; they are essential for movement of the passenger, and limit the possible directions of travel, but a parallel mechanism of driver and road signs exists to choose the route. In a similar way, the ECM and its receptors will act to assemble cells into a functioning tissue, and it seems sensible to have feedback between the organization of the tissue and the final differentiation of cells. Thus, this can ensure that potent digestive enzymes are not released into the organism, and can keep proliferation tied to tissue growth, rather than the metastatic cancerous behavior of individual cells released from these normal constraints. Thus, the ECM contributes to a developmental "morphogenesis checkpoint" that does not proceed with differentiation unless the architecture of the embryo is correct. The crucial function of ECM receptors in development is in the construction of the functioning organism. However, the ECM does make some contributions to the signaling pathways that do make key cell fate decisions, as discussed in the next section.

ECM Modulation of Signaling by Extracellular Peptide Ligands

Almost all patterning and determination of cell fate in embryos is mediated by the reiterative use of secreted peptide ligands from five major 
N.H. Brown

families (TGF $\alpha$; FGF; TGF $\beta$, WNT, and Hh) in combination with direct cell-cell signaling through Notch. Ligands of the TGF $\beta$, WNT, and $\mathrm{Hh}$ families act as morphogens, that is, they induce different cell fates at different concentrations. Although ECM components may not specify cell fate decisions directly, ECM function contributes to the signaling by these secreted peptide ligands.

There are a number of ways that the ECM can contribute rather indirectly to signaling pathways (Fig. 2F). Integrin-mediated adhesion between cell layers could help to keep the source of the ligand in close proximity to the receiving cells, particularly in examples of signaling from mesenchyme to epithelial layers. Adhesion to the ECM may also lead to increased or reduced interaction between receptors and their ligands. It has proved surprisingly difficult to discover on which side of the cell (apical or basolateral) signaling occurs. Although many ligands appear to be secreted apically, transcytosis to the basolateral compartment can be essential for signaling (e.g., Gallet et al. 2008). The subcellular position of the signaling will clearly affect possible crosstalk at the membrane between integrins and other signaling receptors. It is also clear that the ECM could have a profound effect on the shape of morphogen gradients, as the rate of diffusion of the secreted ligands through the extracellular space will be affected by interactions with ECM components (Umulis et al. 2009; Yan and Lin 2009). Binding to ECM components will slow the rate of diffusion, but conversely, the mesh of the ECM, particularly the hydrated polysaccharides, will reduce the volume of the extracellular fluid and increase ligand concentration.

Two components of the ECM, collagen IV and heparan sulfate proteoglycans (HSPGs), have been shown to be directly required for signal transmission by developmental peptide ligands. Collagen IV is an essential mediator of TGF $\beta$ signaling in Drosophila (Wang et al. 2008; Umulis et al. 2009). Direct binding of collagen IV to the TGF $\beta$ ligand Decapentaplegic increases ligand activity in the embryo, while sequestering it in the developing ovary. Mutations in genes encoding enzymes that synthesize the heparan sulfate result in altered signaling by Wnt, Hh, and TGF $\beta$ pathways (for review see Lin 2004). The HSPGs affect the function of these ligands, either by stabilizing them or by affecting their movement to generate morphogen gradients. The different affinities of FGF ligands for heparan sulfate are critical for their formation of gradients that specify distinct aspects of branching morphogenesis in the mammalian salivary gland (Makarenkova et al. 2009). In Drosophila, there are just four HSPGs, of three types: the glycosylphosphatidylinositol (GPI) linked glypicans, Dally and Dally-like; the transmembrane syndecan; and the secreted basement membrane-component perlecan. The different HSPGs are compartmentalized on opposite sides of epithelial layers, with syndecan and perlecan restricted to the basal surfaces of epithelia, and glypicans enriched in the apical compartment. However, transduction of glypicans to basolateral compartments is important for Hh signaling (e.g., Gallet et al. 2008). Loss of laminin function in Zebrafish leads to reduced HSPGs in the basement membrane, which are required to restrict TGF $\beta$ (BMP) signaling (Dolez et al. 2011). Thus, HSPGs appear to regulate signaling on both apical and basal surfaces of epithelia.

ECM Contributions to the Architecture of the Organism: Insulator, Glue, and Structure

Interaction between ECM proteins and their cellular receptors is a key part of shaping the organism during development. Within the developing embryo the ECM can be seen to provide a variety of architectural roles, which I have divided into: insulation of tissue, gluing different cell layers together, and providing structural support to the organism.

\section{Insulation versus Glue}

The surface of cells that faces the body fluid is generally covered by a basement membrane. One of the key functions of this covering is to protect and insulate the plasma membrane (Fig. 2G). The plasma membrane is strongly negatively charged, and sticks well to positively 
charged molecules, as shown by the strong adherence of all varieties of cells to polylysine. Genetic analysis of ECM components has shown that an intact basement membrane is vital to keep tissues freely moving relative to each other. In the Drosophila embryo, the somatic muscles attach at each end to tendon cells via a tendon matrix. However, the basal surfaces of the other (nontendon) epidermal cells are coated with a basement membrane, as are the lateral surfaces of the muscles. When the basement membrane is fragmented by the removal of laminin, then the muscles stick to the basal surface of the epidermis (Prokop et al. 1998). Thus, the basement membrane prevents these different tissues from sticking to each other, and allows them to slide against each other. This is obvious as one observes the transparent larvae crawling; The different internal organs shift and slide over each other. A similar phenomenon has been observed in C. elegans mutant for laminin subunits (Huang et al. 2003). Thus, basement membranes provide a valuable insulator function.

A key feature of ECMs is that once built by cells, the matrix remains as a stable reference point during periods of rapid changes in cell shape or cell movement. For example, within pseudostratified epithelial layers, when cells divide the majority of the cell body moves apically and rounds up. However, the dividing cells maintain a thin process anchored to the basal lamina (e.g., Das et al. 2003; Alexandre et al. 2010), which is likely to aid the subsequent basal movement of the cell bodies of the daughter cells.

In contrast to this insulator function of the ECM, which is characterized by a cell/basement membrane/extracellular fluid boundary, the ECM also serves to glue different cell layers together (Fig. 2H). Thus, the attachment of the muscles in invertebrates is to the epidermis, via integrins and an intervening layer of ECM, whereas in vertebrates, the muscles anchor via more elaborate ECMs, the tendon and bone. In vertebrates the epidermis is linked to the dermis via an intervening BM, whereas adhesion between the basal surface of the two epithelial layers that make insect wings also requires integrin-mediated adhesion via an intervening layer of ECM. Particularly in the smaller invertebrates, in which basal ECM layers are thin $(<40 \mathrm{nM})$, these sites of attachment among cell layers look more like sites of cell-cell adhesion than cell-substrate adhesion (e.g., Prokop et al. 1998). This raises the question of why these contacts form by cell-ECM-cell adhesion, rather than direct cell adhesion.

There are potentially many advantages to gluing cell layers together via an ECM, rather than by direct adhesion among transmembrane proteins on opposing cell layers. One is that the intervening ECM can simultaneously provide glue function and a barrier function, keeping the two cell populations from intermingling. This fits with the concept that cadherin-mediated cell-cell adhesion is a primary level of adhesion among similar cells, whereas cell-ECM-cell is a secondary level of adhesion that links different layers together. A second advantage is that the ECM provides the organism with a valuable mechanism to regulate tissue assembly. Thus, different cell layers may already express the appropriate receptor, yet will be unable to use it to migrate or adhere into a unit until the ECM is synthesized. The ECM components may be produced by the cells that will attach to it, but can also be produced by another cell population, which therefore gains the ability to control the formation or migration of other tissues. For example, in the Drosophila embryo, many ECM proteins are made by hemocytes, and recent work has shown that their ability to migrate is required for them to deposit collagen IV on the developing Malphigian tubules, which in turn is required for the reception of a TGF $\beta$ signal that directs the migration of the Malphigian tubules (Bunt et al. 2011). This action at a distance could be advantageous to permit coordination of tissue assembly across the developing embryo. A third advantage, already mentioned previously, is that the ECM provides a fixed structure that cells can associate with in a dynamic manner. This reflects one of the fascinating aspects of cellular and molecular architecture, the fact that most load-bearing structures still require turnover of the cells and molecules that make up 
N.H. Brown

the structure. Thus, the structures must retain their ability to function while old components are exchanged for new ones.

One consequence of categorizing the ECM as an insulator or glue is that these are opposing functions. This dichotomy shows the need for a mechanism to control whether the cell is coated with a "slippery" or "sticky" ECM. For muscles, different parts of the cell are coated with different kinds of ECM, requiring subcellular control, because the ends attach to a sticky ECM, whereas the lateral sides are coated with a slippery ECM. The mechanisms for this level of control are still poorly understood, because, for example, the same receptors may attach to both. In addition to choosing between insulation and glue, morphogenetic changes require transitions between them. Two informative examples of this are provided by the Drosophila wing imaginal disc, the sac of epithelial cells in the larva that will give rise to the wing and portions of the thorax of the adult fly. In the first example, the tracheal branch slips under the basement membrane to make a close link with the surface of the epithelial layers (Inoue and Hayashi 2007). In the second, the morphogenetic transformation of the wing disc into the wing requires the degradation of the basement membrane and the formation of new ECM that links the two cell layers that will form the dorsal and ventral surfaces of the wing. The initiation of this transformation can be induced by proteolytic degradation of basement membrane (Dominguez-Gimenez et al. 2007 and references therein), suggesting that its presence holds back a tissue transformation that is ready to go. This is an unexpected active role for ECM in morphogenesis, stabilizing an apparently unfavorable tissue shape.

\section{Structural Roles of ECM}

Finally, the ECM plays important structural roles in building animals, particularly in forming the skeleton, both endo and exoskeletons. Skeletons are built with astounding patterns and complexities. The role of ECM in bones and cartilage is an important area that is beyond the scope of this article. As mentioned for the exoskeleton, recent results have shown that it plays an active role in morphogenesis, instead of just providing protective armor. This is exemplified by the role of ZP domain-containing proteins, which specify cell shape and the morphology of actin protrusions that underlie the hairs and bristles on the surface (Plaza et al. 2010). In addition, the production of ball and socket junction via an exoskeleton requires interplay between cellular changes and the production of the apical ECM (Tajiri et al. 2010).

A further example of a structural role provided by the ECM is to create an extracellular space of a particular volume. This is exemplified by the role of the ECM protein Eyes shut, a protein similar to perlecan and agrin, in specifying the distance between photoreceptors within insect eyes (Fig. 2I) (Husain et al. 2006; Zelhof et al. 2006).

\section{CONCLUDING REMARKS}

Even following many years of study, new roles for the ECM in development are continuing to be discovered. In many cases it is still difficult to discern the balance between a role for the ECM in simply providing a permissive structural support or actively directing changes to cell and tissue morphology. The contribution of the mechanotranducing functions of ECM receptors to developmental processes is only beginning to be explored and is an especially important area for future research (see Schwartz 2010; Lu et al. 2011). Having determined the range of functions of the ECM in development, future work will elucidate how the basic machinery of cell-ECM interactions is modified to generate the wide range of developmental functions, from dynamic interactions during cell migration to the formation of stable adhesive interactions that give force-responsive structure to the developing animal.

\section{REFERENCES}

Adams JC, Lawler J. 2011. The thrombospondins. Cold Spring Harb Perspect Biol doi: 10.1101/cshperspect. a009712.

Alexandre P, Reugels AM, Barker D, Blanc E, Clarke JD. 2010. Neurons derive from the more apical daughter in 
asymmetric divisions in the zebrafish neural tube. Nat Neurosci 13: 673-679.

Barros C, Franco S, Müller U. 2011. Extracellular matrix: Functions in the nervous system. Cold Spring Harb Perspect Biol doi: 10.1101/cshperspect.a005108.

Boube M, Martin-Bermudo MD, Brown NH, Casanova J. 2001. Specific tracheal migration is mediated by complementary expression of cell surface proteins. Genes Dev 15: 1554- 1562.

Bradley PL, Myat MM, Comeaux CA, Andrew DJ. 2003. Posterior migration of the salivary gland requires an intact visceral mesoderm and integrin function. Dev Biol 257: 249-262.

Bunch TA, Graner MW, Fessler LI, Fessler JH, Schneider KD, Kerschen A, Choy LP, Burgess BW, Brower DL. 1998. The PS2 integrin ligand tiggrin is required for proper muscle function in Drosophila. Development 125: 1679-1689.

Bunt S, Hooley C, Hu N, Scahill C, Weavers H, Skaer H. 2011. Hemocyte-secreted type IV collagen enhances BMP signaling to guide renal tubule morphogenesis in Drosophila. Dev Cell 19: 296-306.

Chanana B, Graf R, Koledachkina T, Pflanz R, Vorbrüggen G. 2007. $\alpha$ PS2 integrin-mediated muscle attachment in Drosophila requires the ECM protein Thrombospondin. Mech Dev 124: 463-475.

Chiquet-Ehrismann R, Tucker RP. 2011. Tenascins and the importance of adhesion modulation. Cold Spring Harb Perspect Biol doi: 10.1101/cshperspect.a004960.

Das T, Payer B, Cayouette M, Harris WA. 2003. In vivo timelapse imaging of cell divisions during neurogenesis in the developing zebrafish retina. Neuron 37: 597-609.

Davidson LA, Marsden M, Keller R, Desimone DW. 2006. Integrin $\alpha 5 \beta 1$ and fibronectin regulate polarized cell protrusions required for Xenopus convergence and extension. Curr Biol 16: 833-844.

Delon I, Brown NH. 2009. The integrin adhesion complex changes its composition and function during morphogenesis of an epithelium. J Cell Sci 122: 4363-4374.

Denef N, Chen Y, Weeks SD, Barcelo G, Schupbach T. 2008. Crag regulates epithelial architecture and polarized deposition of basement membrane proteins in Drosophila. Dev Cell 14: 354-364.

Devenport D, Brown NH. 2004. Morphogenesis in the absence of integrins: Mutation of both Drosophila beta subunits prevents midgut migration. Development 131: 5405-5415.

Devenport D, Bunch TA, Bloor JW, Brower DL, Brown NH. 2007. Mutations in the Drosophila $\alpha$ PS2 integrin subunit uncover new features of adhesion site assembly. Dev Biol 308: 294-308.

Dolez M, Nicolas JF, Hirsinger E. 2011. Laminins, via heparan sulfate proteoglycans, participate in zebrafish myotome morphogenesis by modulating the pattern of Bmp responsiveness. Development 138: 97-106.

Dominguez-Gimenez P, Brown NH, Martin-Bermudo MD. 2007. Integrin-ECM interactions regulate the changes in cell shape driving the morphogenesis of the Drosophila wing epithelium. J Cell Sci 120: 1061-1071.

Fernandez-Minan A, Martin-Bermudo MD, Gonzalez-Reyes A. 2007. Integrin signaling regulates spindle orientation in Drosophila to preserve the follicular-epithelium monolayer. Curr Biol 17: 683-688.

Fogerty FJ, Fessler LI, Bunch TA, Yaron Y, Parker CG, Nelson RE, Brower DL, Gullberg D, Fessler JH. 1994. Tiggrin, a novel Drosophila extracellular matrix protein that functions as a ligand for Drosophila $\alpha$ PS2 $\beta$ PS integrins. Development 120: 1747-1758.

Francis R, Waterston RH. 1991. Muscle cell attachment in Caenorhabditis elegans. J Cell Biol 114: 465-479.

Gallet A, Staccini-Lavenant L, Therond PP. 2008. Cellular trafficking of the glypican Dally-like is required for fullstrength Hedgehog signaling and wingless transcytosis. Dev Cell 14: 712-725.

Geiger B, Yamada KM. 2011. Molecular architecture and function of matrix adhesions. Cold Spring Harbor Perspect Biol doi: 10.1101/cshperspect.a005033.

Gettner SN, Kenyon C, Reichardt LF. 1995. Characterization of beta pat- 3 heterodimers, a family of essential integrin receptors in C. elegans. J Cell Biol 129: 1127-1141.

Hoang B, Chiba A. 1998. Genetic analysis on the role of integrin during axon guidance in Drosophila. J Neurosci 18: $7847-7855$.

Huang C-C, Hall DH, Hedgecock EM, Kao G, Karantza V, Vogel BE, Hutter H, Chisholm AD, Yurchenco PD, Wadsworth WG. 2003. Laminin $\alpha$-subunits and their role in C. elegans development. Development 130: 3343-3358.

Husain N, Pellikka M, Hong H, Klimentova T, Choe KM, Clandinin TR, Tepass U. 2006. The agrin/perlecanrelated protein eyes shut is essential for epithelial lumen formation in the Drosophila retina. Dev Cell 11:483-493.

Hynes RO, Naba A. Overview of the matrisome- an inventory of ECM constituents functions. Cold Spring Harbor Perspect Biol doi: 10.1101/cshspect.a004903.

Inoue Y, Hayashi S. 2007. Tissue-specific laminin expression facilitates integrin-dependent association of the embryonic wing disc with the trachea in Drosophila. Dev Biol 304: $90-101$.

Kuriyama S, Mayor R. 2008. Molecular analysis of neural crest migration. Philos Trans R Soc Lond B Biol Sci 363: 1349-1362.

Kurpios NA, Ibañes M, Davis NM, Lui W, Katz T, Martin JF, Izpisúa Belmonte JC, Tabin CJ. 2008. The direction of gut looping is established by changes in the extracellular matrix and in cell:cell adhesion. Proc Natl Acad Sci 105: 8499-8506.

Lammermann T, Bader BL, Monkley SJ, Worbs T, WedlichSoldner R, Hirsch K, Keller M, Forster R, Critchley DR, Fassler R, et al. 2008. Rapid leukocyte migration by integrin-independent flowing and squeezing. Nature 453: $51-55$.

Latimer A, Jessen JR. 2009. Extracellular matrix assembly and organization during zebrafish gastrulation. Matrix Biol 29: 89-96.

Lechler T, Fuchs E. 2005. Asymmetric cell divisions promote stratification and differentiation of mammalian skin. Nature 437: 275-280.

Leptin M, Bogaert T, Lehmann R, Wilcox M. 1989. The function of PS integrins during Drosophila embryogenesis. Cell 56: 401-408. 
N.H. Brown

Lin X. 2004. Functions of heparan sulfate proteoglycans in cell signaling during development. Development 131: 6009-6021.

Lu P, Takai K, Weaver VM, Werb Z. 2011. Extracellular matrix degradation and remodeling in development and disease. Cold Spring Harb Perspect Biol doi: 10.1101/cshperspect.a005058.

Makarenkova HP, Hoffman MP, Beenken A, Eliseenkova AV, Meech R, Tsau C, Patel VN, Lang RA, Mohammadi M. 2009. Differential interactions of FGFs with heparan sulfate control gradient formation and branching morphogenesis. Sci Signal 2: ra55.

Marsden M, Burke RD. 1998. The betaL integrin subunit is necessary for gastrulation in sea urchin embryos. Dev Biol 203: $134-148$

Martin D, Zusman S, Li X, Williams EL, Khare N, DaRocha S, Chiquet-Ehrismann R, Baumgartner S. 1999. Wing blister, a new Drosophila laminin $\alpha$ chain required for cell adhesion and migration during embryonic and imaginal development. J Cell Biol 145: 191-201.

Martin-Bermudo MD, Brown NH. 1996. Intracellular signals direct integrin localization to sites of function in embryonic muscles. J Cell Biol 134: 217-226.

Martin-Bermudo MD, Brown NH. 1999. Uncoupling integrin adhesion and signaling: The $\beta$ PS cytoplasmic domain is sufficient to regulate gene expression in the Drosophila embryo. Genes Dev 13: 729-739.

Martin-Bermudo MD, Brown NH. 2000. The localized assembly of extracellular matrix integrin ligands requires cell-cell contact. J Cell Sci 113: 3715-3723.

Martin-Bermudo MD, Alvarez-Garcia I, Brown NH. 1999. Migration of the Drosophila primordial midgut cells requires coordination of diverse PS integrin functions. Development 126: 5161-5169.

Matus DQ, Li XY, Durbin S, Agarwal D, Chi Q, Weiss SJ, Sherwood DR. 2010. In vivo identification of regulators of cell invasion across basement membranes. Sci Signal 3: ra35.

Medioni C, Noselli S. 2005. Dynamics of the basement membrane in invasive epithelial clusters in Drosophila. Development 132: 3069-3077.

Meighan CM, Schwarzbauer JE. 2007. Control of C. elegans hermaphrodite gonad size and shape by vab-3/Pax6mediated regulation of integrin receptors. Genes Dev 21: $1615-1620$.

Meighan CM, Schwarzbauer JE. 2008. Temporal and spatial regulation of integrins during development. Curr Opin Cell Biol 20: 520-524.

Menko AS, Boettiger D. 1987. Occupation of the extracellular matrix receptor, integrin, is a control point for myogenic differentiation. Cell 51: 51-57.

Mirouse V, Christoforou CP, Fritsch C, St Johnston D, Ray RP. 2009. Dystroglycan and perlecan provide a basal cue required for epithelial polarity during energetic stress. Dev Cell 16: 83-92.

Mogensen MM, Tucker JB. 1987. Evidence for microtubule nucleation at plasma membrane-associated sites in Drosophila. J Cell Sci 88: 95-107.

Moussian B. 2010. Recent advances in understanding mechanisms of insect cuticle differentiation. Insect Biochem Mol Biol 40: 363-375.
Niewiadomska P, Godt D, Tepass U. 1999. DE-Cadherin is required for intercellular motility during Drosophila oogenesis. J Cell Biol 144: 533-547.

Page AP, Johnstone IL. 2007. The cuticle. WormBook 19: $1-15$.

Plaza S, Chanut-Delalande H, Fernandes I, Wassarman PM, Payre F. 2010. From A to Z: Apical structures and zona pellucida-domain proteins. Trends Cell Biol 20: 524-532.

Prokop A, Martin-Bermudo MD, Bate M, Brown NH. 1998. Absence of PS integrins or laminin A affects extracellular adhesion, but not intracellular assembly, of hemiadherens and neuromuscular junctions in Drosophila embryos. Dev Biol 196: 58-76.

Roote CE, Zusman S. 1995. Functions for PS integrins in tissue adhesion, migration, and shape changes during early embryonic development in Drosophila. Dev Biol 169: 322-336.

Rozario T, Dzamba B, Weber GF, Davidson LA, DeSimone DW. 2009. The physical state of fibronectin matrix differentially regulates morphogenetic movements in vivo. $\mathrm{Dev}$ Biol 327: 386-398.

Sakai T, Larsen M, Yamada KM. 2003. Fibronectin requirement in branching morphogenesis. Nature 423: 876-881.

Schwartz MA. 2010. Integrins and extracellular matrix in mechanotransduction. Cold Spring Harb Perspect Biol doi: $10.1101 /$ cshperspect.a005066.

Schwarzbauer JE, DeSimone DW. 2011. Fibronectins, their fibrillogenesis and in vivo functions. Cold Spring Harb Perspect Biol doi: 10.1101/cshperspect.a005041.

Sorrosal G, Perez L, Herranz H, Milan M. 2010. Scarface, a secreted serine protease-like protein, regulates polarized localization of laminin A at the basement membrane of the Drosophila embryo. EMBO Rep 11: 373-379.

Streuli CH. 2009. Integrins and cell-fate determination. J Cell Sci 122: 171-177.

Streuli CH, Bailey N, Bissell MJ. 1991. Control of mammary epithelial differentiation: Basement membrane induces tissue-specific gene expression in the absence of cell-cell interaction and morphological polarity. J Cell Biol 115: 1383-1395.

Subramanian A, Wayburn B, Bunch T, Volk T. 2007. Thrombospondin-mediated adhesion is essential for the formation of the myotendinous junction in Drosophila. Development 134: 1269-1278.

Tajiri R, Misaki K, Yonemura S, Hayashi S. 2010. Dynamic shape changes of ECM-producing cells drive morphogenesis of ball-and-socket joints in the fly leg. Development 137: 2055-2063.

Tepass U, Hartenstein V. 1994. The development of cellular junctions in the Drosophila embryo. Dev Biol 161: 563-596.

Umulis D, O'Connor MB, Blair SS. 2009. The extracellular regulation of bone morphogenetic protein signaling. Development 136: 3715-3728.

Wang X, Harris RE, Bayston LJ, Ashe HL. 2008. Type IV collagens regulate BMP signalling in Drosophila. Nature 455: 72-77. 
Watt FM, Fujiwara H. 2011. Cell-extracellular matrix interactions in normal and diseased skin. Cold Spring Harb Perspect Biol doi: 10.1101/cshperspect.a005124.

Wickström SA, Rodovanac K, Fässler R. 2011. Genetic analyses of integrin signaling. Cold Spring Harb Perspect Biol doi: 10.1101/cshperspect.a005116.

Xu R, Nelson CM, Muschler JL, Veiseh M, Vonderhaar BK, Bissell MJ. 2009. Sustained activation of STAT5 is essential for chromatin remodeling and maintenance of mammary-specific function. J Cell Biol 184: 57-66.

Yan D, Lin X. 2009. Shaping morphogen gradients by proteoglycans. Cold Spring Harb Perspect Biol 1: a002493.

Yin C, Kikuchi K, Hochgreb T, Poss KD, Stainier DYR 2010. Hand2 regulates extracellular matrix remodeling essential for gut-looping morphogenesis in Zebrafish. Developmental Cell 18: 973-984.

Yu W, Datta A, Leroy P, O’Brien LE, Mak G, Jou TS, Matlin KS, Mostov KE, Zegers MM. 2005. Beta1-integrin orients epithelial polarity via Racl and laminin. Mol Biol Cell 16: 433-445.

Yurchenco PD. 2011. Basement membranes: Cell scaffoldings and signaling platforms. Cold Spring Harb Perspect Biol doi: 10.1101/cshperspect.a004911.

Zelhof AC, Hardy RW, Becker A, Zuker CS. 2006. Transforming the architecture of compound eyes. Nature 443: 696-699.

Zhang H, Labouesse M. 2010. The making of hemidesmosome structures in vivo. Dev Dyn 239: 1465-1476. 


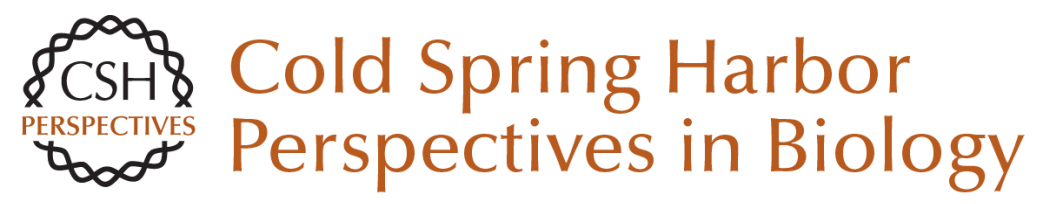

\title{
Extracellular Matrix in Development: Insights from Mechanisms Conserved between Invertebrates and Vertebrates
}

\author{
Nicholas H. Brown
}

Cold Spring Harb Perspect Biol 2011; doi: 10.1101/cshperspect.a005082 originally published online September 14, 2011

\section{Subject Collection Extracellular Matrix Biology}

Extracellular Matrix in Development: Insights from Mechanisms Conserved between Invertebrates and Vertebrates Nicholas H. Brown

Extracellular Matrix Proteins in Hemostasis and Thrombosis Wolfgang Bergmeier and Richard O. Hynes

The Thrombospondins Josephine C. Adams and Jack Lawler

Cross Talk among TGF- $\beta$ Signaling Pathways, Integrins, and the Extracellular Matrix John S. Munger and Dean Sheppard

Heparan Sulfate Proteoglycans Stephane Sarrazin, William C. Lamanna and Jeffrey D. Esko

\section{The Collagen Family} Sylvie Ricard-Blum

Tenascins and the Importance of Adhesion Modulation Ruth Chiquet-Ehrismann and Richard P. Tucker Integrin Structure, Activation, and Interactions lain D. Campbell and Martin J. Humphries
Extracellular Matrix Degradation and Remodeling in Development and Disease

Pengfei Lu, Ken Takai, Valerie M. Weaver, et al.

Overview of the Matrisome--An Inventory of Extracellular Matrix Constituents and Functions Richard O. Hynes and Alexandra Naba

Integrins in Cell Migration Anna Huttenlocher and Alan Rick Horwitz

Fibronectins, Their Fibrillogenesis, and In Vivo Functions Jean E. Schwarzbauer and Douglas W. DeSimone

Extracellular Matrix: Functions in the Nervous System Claudia S. Barros, Santos J. Franco and Ulrich Müller

Molecular Architecture and Function of Matrix Adhesions Benjamin Geiger and Kenneth M. Yamada

Cell-Extracellular Matrix Interactions in Normal and Diseased Skin

Fiona M. Watt and Hironobu Fujiwara

Genetic Analyses of Integrin Signaling Sara A. Wickström, Korana Radovanac and Reinhard Fässler

For additional articles in this collection, see http://cshperspectives.cshlp.org/cgi/collection/

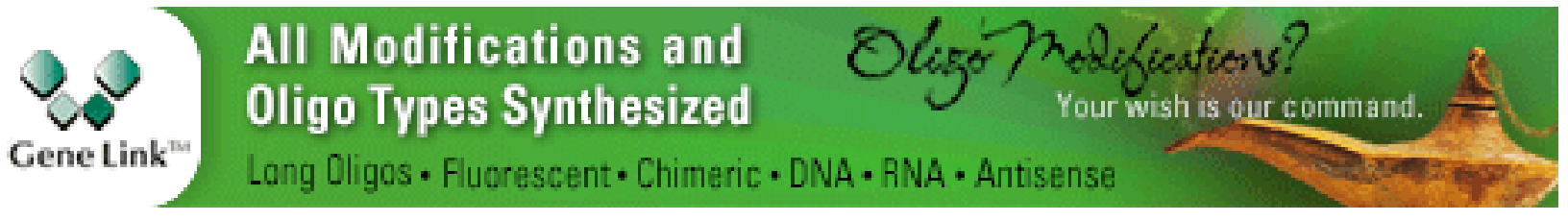

